(C) 2019 Universidad Nacional Autónoma de México, Facultad de Estudios Superiores Zaragoza.

Este es un artículo Open Access bajo la licencia CC BY-NC-ND (http://creativecommons.org/licenses/by-nc-nd/4.0/).

TIP Revista Especializada en Ciencias Químico-Biológicas, 22: 1-17, 2019.

DOI: $10.22201 /$ fesz.23958723e.2019.0.173

\title{
Criterios y estrategias tecnológicas para la incorporación y supervivencia de probióticos en frutas, cereales y sus derivados
}

\author{
Valeria Castillo-Escandón ${ }^{1}$, Silvia Guadalupe Fernández-Michel ${ }^{1}$, \\ María Cristina Cueto- Wong ${ }^{1}$ y Gabriela Ramos-Clamont Montfort ${ }^{2 *}$ \\ ${ }^{1}$ Laboratorio de Ciencia y Tecnología de Alimentos Orientados a la Salud. Facultad de Ciencias Biológicas. \\ Universidad Autónoma de Coahuila, México. ${ }^{2}$ Laboratorio de Bioquímica de Proteínas y Glicanos, Coordinación \\ de Ciencia de los Alimentos, Centro de Investigación en Alimentación y Desarrollo, A. C., Carretera Gustavo \\ Enrique Astiazarán \# 46, Col. La Victoria, Hermosillo, Sonora 83304, México. E-mail: *gramos@ciad.mx
}

\begin{abstract}
RESUMEN
Los alimentos a los que se les añaden probióticos (bacterias benéficas) constituyen uno de los sectores más importantes de los alimentos funcionales. Los productos lácteos son los principales vehículos para estas bacterias que producen un efecto benéfico a la salud, cuando se consumen vivas y en cantidades suficientes para adherirse al colon. Sin embargo, cada día crece el interés por desarrollar alimentos no lácteos como vehículo para probióticos. Los productos de origen vegetal son una buena alternativa para estas innovaciones. Tienen la ventaja de que son muy aceptados y accesibles para la población. Adicionalmente, representan una alternativa de consumo para poblaciones con dietas restringidas. Sin embargo, la incorporación de probióticos a estos productos requiere considerar varios criterios y vencer retos tecnológicos con la finalidad de conservarlos funcionalmente activos.
\end{abstract}

Palabras clave: probióticos, alimentos funcionales, viabilidad, frutas, verduras y cereales.

Criteria and technological strategies for the incorporation and survival of probiotics in fruits, cereals and their products

\begin{abstract}
Foods to which probiotics (beneficial bacteria) have been added constitute one of the most important sectors of functional foods. Dairy products are the main vehicles for these bacteria that produce a beneficial effect on health, when consumed alive and in sufficient quantities to adhere to the colon. However, every day there is a growing interest in developing nondairy foods as a vehicle for probiotics. The products of vegetable origin are a good alternative for these innovations. They have the advantage of being very accepted and accessible for the population. In addition, they represent a consumption alternative for populationwith restricted diets. However, the incorporation of probiotics to these products requires to consider several criteria and to overcome technological challenges in order to keep them functionally active.
\end{abstract}

Key words: probiotics, functional foods, viability, fruits, vegetables and cereals. 


\section{INTRODUCCIÓN}

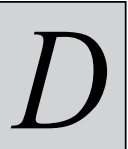

urante siglos hemos consumido microorganismos vivos contenidos en diversos tipos de leches fermentadas. Los estudios realizados por el científico Elie Metchnikoff a partir de 1907, permitieron relacionar la ingesta de estas bacterias lácticas, con un efecto benéfico para la salud. A partir de entonces se han llevado a cabo gran cantidad de estudios que evidencian la presencia e importancia de consorcios microbianos que habitan el tracto intestinal, cuyas funciones son esenciales para nuestro desarrollo, salud y bienestar. Otras investigaciones demuestran que el consumo de ciertas bacterias benéficas, conocidas como probióticos, pueden contribuir a mantener o restablecer la homeostasis de dichos consorcios (Hun, 2009; Fitzpatrick, Small, Greene, Karpa, \& Keller, 2012; Kechagia et al., 2013). Este hecho ha interesado a la industria de alimentos, que ha desarrollado con gran éxito, una gran variedad de productos lácteos, como vehículo acarreador de probióticos. Actualmente, el interés se extiende hacia la producción de formulaciones no lácteas que contengan a estas bacterias, particularmente las de origen vegetal por ser muy aceptadas por todo tipo de consumidores y por presentar alternativas de consumo para vegetarianos y veganos o para poblaciones que no pueden consumir productos lácteos. En esta revisión se analizan los principales criterios y estrategias tecnológicas para incorporar y preservar la viabilidad de los probióticos, en frutas, vegetales y cereales.
Probióticos: Definición y efectos benéficos a la salud

La definición más ampliamente aceptada para los probióticos es la acordada por el panel de expertos comisionados en 2001 por la Organización de las Naciones Unidas para la Agricultura y Alimentación (FAO, Food and Agriculture Organization) reconocida por la Organización Mundial de la Salud (WHO, World Health Organization). Ésta, indica que los probióticos son microorganismos vivos, que cuando se consumen en cantidades adecuadas, producen un efecto benéfico a la salud (FAO/WHO, 2001). De acuerdo con esta definición y a pesar de tener algunas características funcionales, la biomasa muerta no se considera probiótico, sino paraprobiótico, conocido también como probiótico no viable, probiótico fantasma o probiótico inactivado (Aguilar-Toalá et al., 2018).

Son varios los efectos benéficos a la salud que producen los probióticos. Los principales se esquematizan en la Figura 1. Sin embargo, es importante resaltar que dichos efectos son especie y cepa específicos y deben probarse tanto in vitro como in vivo (Bagon et al., 2018).

\section{Criterios de selección de probióticos para consumo humano}

Cada cepa que quiera utilizarse como probiótico para consumo humano, debe cumplir con una serie de requisitos de seguridad (inocuidad), fisiológicos, funcionales y tecnológicos. Primero,

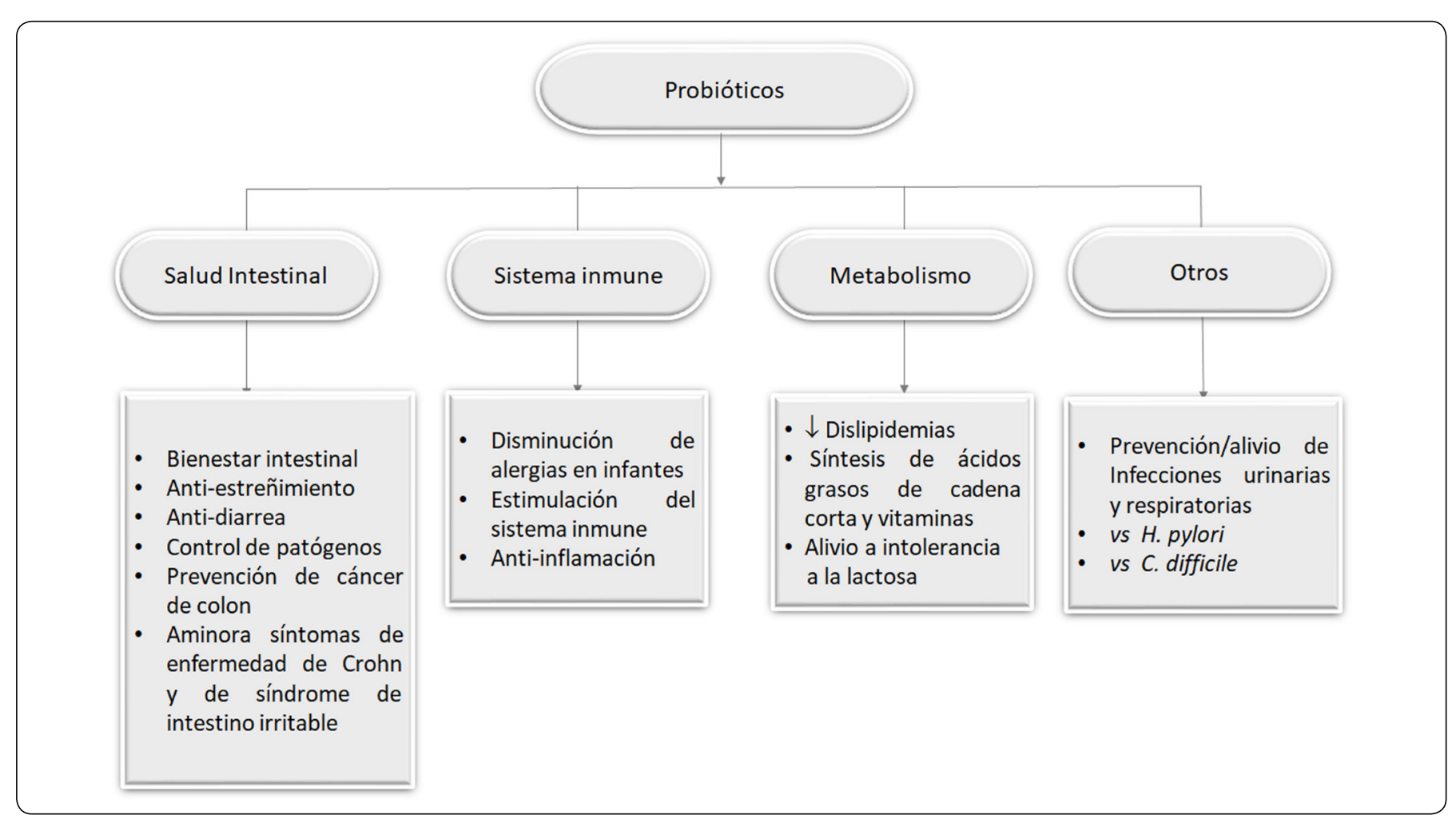

Figura 1. Beneficios a la salud atribuidos al consumo de probióticos. Fuente: Adaptado de Lebaka, Wee, Narala \& Joshi (2018). 
es necesario realizar una identificación fenotípica y genotípica precisa del microorganismo (género, especie y cepa). Además, una clasificación taxonómica utilizando la nomenclatura correcta, que incluya el origen, hábitat y fisiología de la especie (Morelli, 2007).

La búsqueda inicial y selección de probióticos implica ensayos de: a) utilización de carbohidratos y proteínas, b) estabilidad fenotípica y genotípica, incluida la estabilidad de los plásmidos, c) detección de resistencia a antibióticos, d) inmunogenicidad, e) inhibición del crecimiento de patógenos y saprófitos, f) producción de bacteriocinas u otras sustancias antimicrobianas g) resistencia al ácido y a sales biliares, h) capacidad para hidrolizar sales biliares e i) existencia de posibles factores de virulencia (Sharma, Mahajan, Attri \& Goel, 2017). Otros análisis muy importantes son los de adhesión, que comprenden ensayos de autoagregación, hidrofobicidad superficial, adhesión a mucosas y células intestinales, entre otros. Estos análisis presentan una idea de la capacidad de colonización de la cepa probiótica candidata y por tanto, de la duración de su efectividad en el intestino del huésped (Xu, Jeong, Lee \& Ahn, 2009).

Es necesario demostrar que el probiótico candidato no producirá ningún daño a la salud del consumidor. Esto se logra primero, a través de ensayos in vitro que prueben la ausencia de actividad patogénica (por ejemplo, actividad hemolisante, producción de enterotoxinas, patogenicidad serológica). Después de los ensayos in vitro, se realizan ensayos preclínicos con modelos animales y finalmente los ensayos clínicos con humanos (Ranadheera, Baines \& Adams, 2010). Este tipo de estudios (in vitro, con modelos animales y en humanos), con los protocolos adecuados, también deben hacerse, para determinar los beneficios que produce la cepa al consumidor (Sharma, Mahajan, Attri \& Goel, 2017).

Adicionalmente, se requiere la determinación de las características tecnológicas de la cepa para su uso en alimentos. Esta caracterización, incluye: determinar su estabilidad genética, la conservación de sus propiedades funcionales y de su viabilidad durante el procesamiento y almacenamiento del vehículo (por ejemplo, alimento), que contenga al probiótico. Además, la resistencia al ataque de los fagos, la capacidad para ser producida a gran escala y la ausencia de metabolitos que puedan deteriorar a las características sensoriales del vehículo al que se añadirán (Ranadheera, Baines \& Adams, 2010; Sánchez, Fernández-García, Margolles, de los ReyesGavilán \& Ruas-Madiedo, 2010).

\section{Los alimentos como vehículos para probióticos}

Los productos comerciales que contienen probióticos utilizan como vehículo a suplementos y alimentos. Los suplementos se consumen como polvos, tabletas o cápsulas; contienen hasta $10^{10} \mathrm{UFC} / \mathrm{g}$ de uno o una mezcla de probióticos. Por su parte, los alimentos a los que se les añaden probióticos, son principalmente de origen lácteo (Foligné, Daniel \& Pot, 2013). Destacan, por su aceptación comercial, el yogurt y las leches fermentadas; otros que cada vez se consumen más son los quesos, postres congelados y helados (Sanders \& Marco, 2010).

Las principales especies patentadas de probióticos que se añaden a productos lácteos son: Lactobacillus jhonsoni NCC533, L. casei Shirota, L. rhamnosus GG, L. acidophilus LA-5, L. reuteri ATTC 55730, L. brevis KB290, Bifidobacterium breve, Yakult, B. longum BB536, B. animalis ssp. B. lactis BB-12, B. infantis 35624, L. casei DN-114 001 ("L. casei Immunitas"), B. animalis DN173 010 ("Bifidis regularis") y L. plantarum 299v (McFarland, Evans \& Goldstein, 2018).

En general, el consumo de alimentos probióticos es mayor en Asia, Australia y Europa del Este (Euromonitor, 2015). Sin embargo, las ventas crecen día con día en el continente americano, ocupando los primeros lugares de consumo en Estados Unidos de Norteamérica, Brasil, Canadá y México, respectivamente. Sólo en 2014, las ventas al por menor de alimentos probióticos, en el continente americano, fueron de 10.8 billones de dólares americanos, con un crecimiento anual estimado para el 2019 de $30.5 \%$ (Feldman, 2015). En ese mismo año, las ventas al detalle en todo el mundo fueron de 43.3 billones de dólares americanos, con un crecimiento anual estimado para el 2019 del $54.3 \%$ (Hui, 2015).

\section{Productos no lácteos como vehículos para probióticos} El aumento de personas con intolerancia a la lactosa, dislipidemias, alergia a las proteínas lácteas y de aquellas que prefieren un consumo vegetariano o uno vegano, ha conducido al desarrollo de alimentos probióticos no-lácteos. Este es un nuevo nicho de oportunidad para la comercialización de alimentos funcionales. Incluye a una gran cantidad de matrices alimentarias y tipos de alimentos (Figura 2) de diferente composición química y contenido de bioactivos. Entre ellos destacan los productos de origen vegetal (Min, Bunt, Mason \& Hussain, 2018).

En la Tabla I se agrupan alimentos no-lácteos que contienen probióticos y que actualmente se comercializan en los mercados internacionales. Varios de estos alimentos son vehículos para los géneros de Lactobacillus y Bifidobacterium que se utilizan en productos lácteos (Papizadeh, Rohani, Nahrevanian, Javadi \& Pourshafie, 2017). Otra especie que destaca actualmente por su resistencia a ambientes adversos, es el Bacillus coagulans, conocido anteriormente como Lactobacillus sporogenes. Este microorganismo comparte características, tanto de la familia Lactobacillaceae como de la Bacillaceae (Kapse, Engineer, Gowdaman, Wagh \& Dhakephalkar, 2018). B. coagulans produce la bacteriocina 


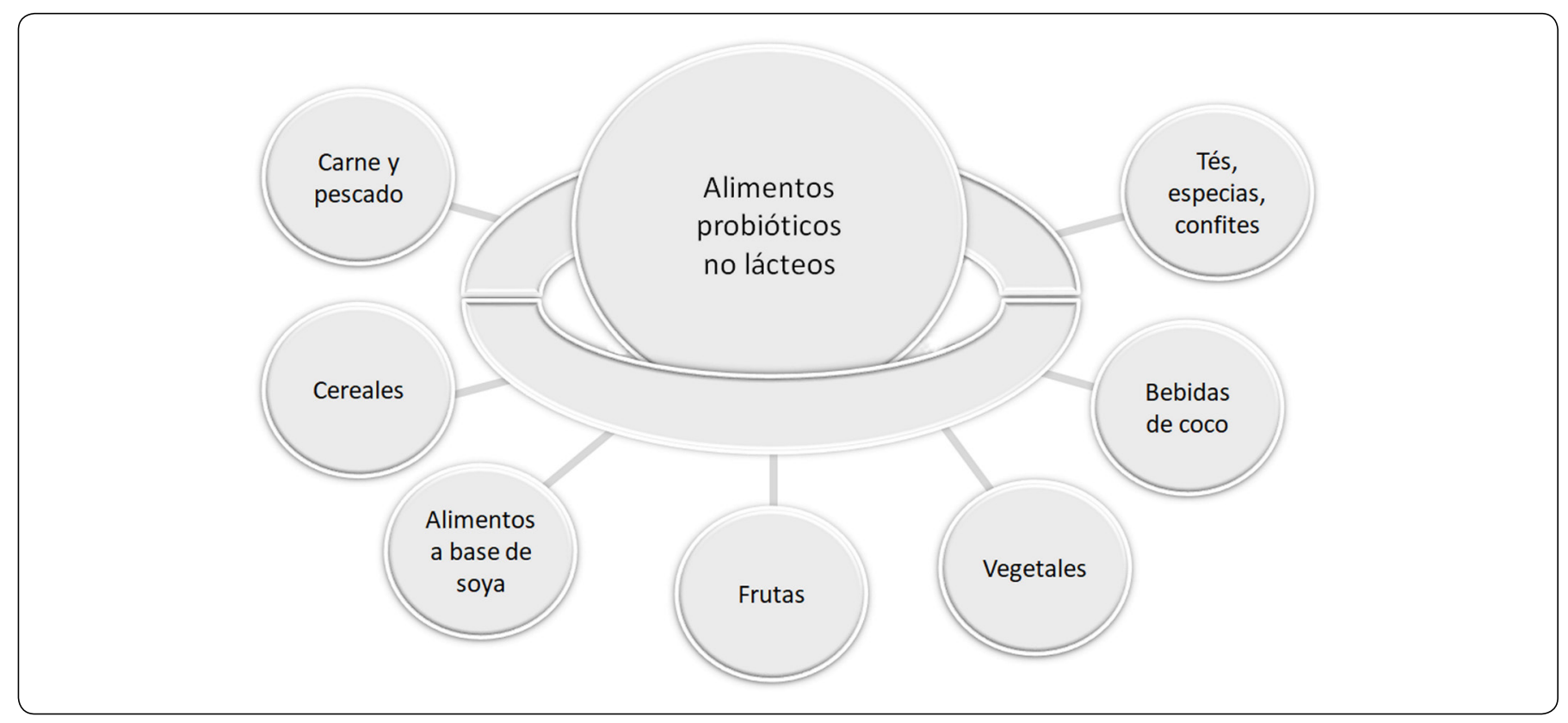

Figura 2. Alimentos funcionales no lácteos utilizados como vehículo de probióticos. Fuente: Adaptado de Min, Bunt, Mason \& Hussain (2018).

coagulina, que controla el crecimiento de patógenos intestinales (Cutting, 2011). También, reduce el dolor abdominal en pacientes con síndrome del intestino irritable y existe evidencia de que aminora los síntomas de diarrea producida por Clostridium difficile (Hun, 2009; Fitzpatrick, Small, Greene, Karpa \& Keller, 2012).

La capacidad de formar esporas le confiere a Bacillus coagulans una mayor resistencia a altas temperaturas y medios con un $\mathrm{pH}$ bajo (Cutting, 2011). Lo anterior, aunado a sus propiedades probióticas, ha sido determinante para que salgan al mercado varios suplementos conteniendo a esta bacteria. Entre los principales se encuentran: Lactospore (Sabrinsa, Corp., EUA), Neolactoflorene (Montefarmaco Inc. Italia) y Sustenex (Ganeden, Biotech, EUA). Este último, contiene a la cepa $B$. coagulans GanedenBC $\mathrm{C}^{30} \mathrm{o} \mathrm{BC}^{30}$ patentada y reconocida como inocua o generalmente segura (GRAS), en los Estados Unidos de Norteamérica (Endres et al., 2009; 2011). Como se observa en la Tabla I, BC ${ }^{30}$ está siendo utilizado comercialmente en alimentos con probióticos que requieren de calentamiento, ya sea durante su producción (por ejemplo galletas) o durante su elaboración (por ejemplo tés). Es importante recordar que el efecto probiótico de las bacterias es cepa específico (Bagon et al., 2018). Por tanto el genoma de diferentes cepas de $B$. coagulans, y sus propiedades probióticas, están siendo actualmente investigadas con la finalidad de determinar si son aptas para su uso en alimentos (Yao, Gao \& Zhang, 2016; Kapse, Engineer, Gowdaman, Wagh \& Dhakephalkar, 2018).

\section{Aspectos a considerar para incorporar probióticos en alimentos no lácteos}

Para la industria alimentaria, cualquier alimento que sea consumido regularmente por la población, es un buen vehículo para los probióticos. Por ello, existe gran interés en el desarrollo de nuevos productos. Sin embargo, deben considerarse varios factores para que el producto sea un éxito. Entre ellos destacan, además de los criterios de selección previamente mencionados de inocuidad y efectividad, factores mercadotécnicos, regulatorios y tecnológicos (Augustin \& Sanguansri, 2015).

\section{Aspectos mercadotécnicos}

Antes de desarrollar el producto que contenga un probiótico debe decidirse el mercado al que será dirigido; por ejemplo, si será regional o global, si se producirá para un mercado masivo o exclusivamente para un sector determinado de la población como edad, religión, alimentación especial, grupos con enfermedades específicas, etc. (Hoffman, 2008; Augustin \& Sanguansri, 2015). Es importante además: a) comunicar de manera clara y sencilla el beneficio a la salud que conferirá el producto, b) considerar que sea competitivo en todas las plataformas, c) con características sensoriales, conveniencia y precios adecuados, d) publicidad y manera de promoverla, e) lealtad a la marca, f) conocimiento de la competencia y g) control de calidad (Granato, Branco, Nazzaro, Cruz \& Faria, 2010). 
Tabla I. Productos no lácteos comercialmente disponibles, que contienen probióticos.

\begin{tabular}{|c|c|c|}
\hline Producto & Compañía & Probiótico \\
\hline Chocolate & Sakara & $\begin{array}{l}\text { Lactobacillus acidophilus, Bifidobacterium } \\
\text { bifidum, B. lactis, B. longum }\end{array}$ \\
\hline Chocolate dietético & ISOWUEY & B. lactis HN019 \\
\hline Chocolate & Healthy Delight & Bacillus coagulans $30\left(\mathrm{BC}^{30}\right)$ \\
\hline Chocolate & Lal'food & L. acidophillus Rosell-52 encapsulado \\
\hline Bebidas de coco y coco combinado con otros sabores & Harmless Harvest & $\begin{array}{l}\text { BC } 30, \text { L. acidophilus, L. casei, L. bulgaricus, } \\
\text { B. lactis, B. bifidum, L. rhamnosus, } \\
\text { Streptococcus thermophilus }\end{array}$ \\
\hline Snacks de manzana, barras de avena, chocolates & Bethy Lou's & $\mathrm{BC}^{30}$ \\
\hline Gomitas, chocolates & Schiff & $\mathrm{BC}^{30}$ \\
\hline $\begin{array}{l}\text { Bebida de soya fermentada } \\
\text { Bio.K }+{ }^{\circledR}\end{array}$ & DietSpotlight & L. acidophilus, L. casei, L rhamnosus \\
\hline $\begin{array}{l}\text { Bebida energizante } \\
\text { Innergyc Biotic (quinoa, arroz integral, proteína de chícharo) }\end{array}$ & Body Ecology & L. acidophilus, L. delbrueckii \\
\hline muffins de varios sabores & Flap Jacket & $\mathrm{BC}^{30}$ \\
\hline $\begin{array}{l}\text { Cereal para desayuno Special K con frutos rojos y } \\
\text { duraznos }\end{array}$ & Kellogg's & B. lactis \\
\hline Canela en polvo & Eat spice & $\mathrm{BC}^{30}$ \\
\hline Té de limón y jengibre & Bigelow & $\mathrm{BC}^{30}$ \\
\hline Granola con probióticos & Purely Elizabeth & $\mathrm{BC}^{30}$ \\
\hline $\begin{array}{l}\text { Cereal de avena para consumo de bebés con DHA y } \\
\text { probióticos }\end{array}$ & Gerber & B. lactis \\
\hline Palomitas de maíz & Silver Fern & Bacillus subtilis HU58, Bacillus coagulans \\
\hline Galletas con chispas de chocolate & Lesser evil & $\mathrm{BC}^{30}$ \\
\hline Galletas de trigo & Natural products & $\mathrm{BC}^{30}$ \\
\hline
\end{tabular}

Adaptada de Dey (2018).

\section{Aspectos legislativos}

Referente a la legislación, los probióticos están clasificados como suplementos alimenticios y su regulación varía de país en país. Sin embargo, se enfoca más a legitimar los efectos benéficos del producto, que en garantizar su eficacia, inocuidad y calidad (de Simone, 2018). A pesar de que la inocuidad de los probióticos y su efectividad para mejorar la salud humana ha sido revisada por el panel de expertos de la FAO y la OMS (FAO/WHO, 2006), queda mucho por hacer para garantizar que los probióticos consumidos en los alimentos sean eficaces para el propósito que se están vendiendo, ya que su principal problema es mantenerlos vivos hasta que lleguen al consumidor (Granato, Branco, Nazzaro, Cruz \& Faria, 2010). Antes de lanzar el producto al mercado, debe de conocerse la regulación nacional e internacional. Si el microorganismo no ha sido añadido antes a los alimentos, deberá pasar por el cumplimiento de los criterios de selección. Es importante también, conocer cuáles serán las obligaciones legales del productor del alimento (Augustin \& Sanguansri, 2015).
Referente a México, no existe una norma específica que regule la incorporación de probióticos a los alimentos, ni que garantice que estos lleguen viables al consumidor. En general, los productores se apegan a la Norma oficial para el etiquetado de productos (NOM-051-SCFI/SSA1-2010a), a la norma para alimentos y bebidas no alcohólicas con modificaciones en su composición. Especificaciones nutrimentales (NOM-086SSA1-1994) y a la norma implementada para leche y productos lácteos (NOM-243-SSA1-2010b). En la Tabla II se presentan algunas de las principales instancias de diferentes países, relacionadas con la regulación de la adición de probióticos a los alimentos. Es importante resaltar la necesidad de mejorar las regulaciones en todos los países y estandarizarlas a nivel internacional.

\section{Aspectos tecnológicos}

Los aspectos tecnológicos a contemplar en la adición de probióticos a los alimentos se enfocan principalmente en: a) la selección de la cepa y la cantidad de inóculo a añadir, 
Tabla II. Algunas instancias que regulan el uso de probióticos en diferentes países.

\begin{tabular}{|l|l|}
\hline \multicolumn{1}{|c|}{ País } & \multicolumn{1}{c|}{ Instancia } \\
\hline Comunidad Económica Europea & Autoridad Europea de Inocuidad Alimentaria (EFSA*) \\
\hline Estados Unidos de Norteamérica & Administración de Medicamentos y Alimentos (FDA*) \\
\hline Canadá & Agencia Canadiense para Inspección de Alimentos (CFIA*) \\
\hline Chile & Instituto de Salud Pública (ISP) \\
\hline Argentina & Administración Nacional de Medicamentos, Alimentos y Tecnología Médica (ANMAT) \\
\hline Japón & Ministerio de Salud Trabajo y Bienestar (MHLW*) \\
\hline India & $\begin{array}{l}\text { Consejo Indio de Medicina (ICMR*)/ Departamento de Biotecnología (DBT*). Guía } \\
\text { para la regulación de probióticos en alimentos }\end{array}$ \\
\hline China & Administración de Medicamentos y Alimentos del Estado (SFDA*) \\
\hline Malasia & $\begin{array}{l}\text { División de Inocuidad y Calidad de Alimentos } \\
\text { (FSQD*), Autoridad para el Control de Medicamentos (DCA*), } \\
\text { Oficina Nacional de Control Farmacéutico (NPCB*) }\end{array}$ \\
\hline Instancias Internacionales & $\begin{array}{l}\text { Organización de las Naciones Unidas para la Agricultura y la Alimentación/Organización } \\
\text { Mundial de Salud (FAO/WHO*); Organización Mundial de Gastroenterología (WGO*); } \\
\text { Instituto Internacional para las Ciencias de la Vida (ILSI*) }\end{array}$ \\
\hline
\end{tabular}

* Siglas en inglés. Fuente: Elaboración propia.

b) su habilidad para crecer en la matriz alimentaria (por ejemplo pulpa de fruta, chocolate, cereal etc.) en la que se quiera incorporar, c) al impacto que tendrá sobre las características sensoriales y la aceptación del producto por el consumidor, d) a la manera (polvo, cultivo, asperjado) y etapa del proceso en que los microorganismos se añadirán al alimento y e) al impacto que las características del alimento, del proceso y de las condiciones de almacenamiento en vida de anaquel, tendrán sobre la viabilidad del probiótico (Augustin \& Sanguansri, 2015).

\section{Importancia de mantener a los probióticos viables}

A fin de ejercer su efecto benéfico, los probióticos tienen que llegar vivos y en cantidad suficiente a su sitio de acción. Una vez allí, deben adherirse al epitelio intestinal, estableciendo un "diálogo bioquímico" con su hospedero. Este intercambio de señales moleculares, aunado a la exclusión competitiva con los patógenos, por los sitios de adhesión intestinal y a la producción de antimicrobianos, constituyen eventos indispensables para que el probiótico realice su función (Champagne, Ross, Saarela, Hansen \& Charalampopoulos, 2011).

No existe información suficiente para determinar cuál es la concentración adecuada, ni legislación que indique la concentración de probióticos vivos que deba contener el alimento al momento de su consumo. En general, la industria alimentaria ha adoptado la cantidad de $10^{6} \mathrm{UFC} /$ $\mathrm{mL}$ o g, que también coincide con las recomendaciones de la Administración de Medicamentos y Alimentos (FDA, Food and Drug Administration) de los Estados Unidos de Norteamérica (Tripathi \& Giri, 2014). También existe el consenso de la Asociación Científica Internacional para Probióticos y Prebióticos (ISAPP, por sus siglas en inglés), acerca de que la ingesta diaria de probióticos debe estar entre $10^{8}$ y $10^{9}$ células viables, lo que se traduce en un consumo diario de alrededor de $100 \mathrm{~g}$ de un alimento que contenga probióticos (Hill et al., 2014).

A partir de estos consensos, existen investigaciones orientadas a determinar si el contenido de probióticos viables que consumimos en los alimentos comerciales es el adecuado y el determinado en la etiqueta. Varios trabajos demuestran que no es así, indicando concentraciones de hasta $3 \log \mathrm{UFC} / \mathrm{g}$ o $\mathrm{mL}$, menores a las recomendaciones mencionadas (Begum, Jakaria, Anisuzzaman, Islam \& Mahmud, 2015; Fredua-Agyeman, Parab \& Gaisford, 2016). Más aún, el grupo de trabajo sobre probióticos y prebióticos de la Sociedad Europea para la Gastroenterología, Hepatología y Nutrición (ESPGHAN, European Society for Pediatric Gastroenterology, Hepatology and Nutrition, por sus siglas en inglés) encontró en sus investigaciones que, además de no contar con las cuentas viables suficientes, algunos alimentos presentaron errores de etiquetado en cuanto a la cepa probiótica y, en algunos casos, contaminación con otros microorganismos (Kolacek et al., 2017). Lo anterior obliga a establecer un control de calidad más riguroso en los alimentos probióticos y en buscar alternativas para garantizar la viabilidad de estos microorganismos, hasta su llegada al lugar de acción.

Por lo anterior, el desarrollo de alimentos que contengan probióticos debe considerar tanto el efecto que los metabolitos producidos por la bacteria tenga sobre las 
características sensoriales del alimento, como: a) la previsión de interacciones indeseables entre la bacteria y la matriz alimenticia, que puedan afectar su viabilidad, b) a limitar la pérdida de viabilidad del probiótico durante el procesamiento del alimento y vida de anaquel, estableciendo los controles de calidad adecuados y c) a buscar estrategias para proteger al microorganismo de su paso a través del tracto gastrointestinal (Sanders \& Marco 2010; Augustin \& Sanguansri, 2015).

Una vez consumido, la supervivencia del probiótico dependerá principalmente de su resistencia a las condiciones del tracto gastrointestinal. Afectan, particularmente, el entorno ácido del estómago y a la acción de las sales biliares en el intestino (Lahtinen, 2012). También influyen la intervención de enzimas pancreáticas, el estado del sistema inmune del consumidor y la composición de su microbiota gastrointestinal. Estos factores son difíciles de controlar, sobre todo si el vehículo en el que viene adicionado el probiótico (matriz alimentaria), no le imparte la suficiente protección hasta su llegada al sitio de acción, que principalmente se encuentra en el colon (Sanders $\&$ Marco, 2010).

\section{Supervivencia de probióticos en matrices no lácteas}

La generación de alimentos no-lácteos como acarreadores de probióticos requiere de investigación básica y aplicada. Ésta, debe garantizar el desarrollo de una buena formulación y un producto realmente saludable, que conserve la viabilidad del probiótico (Meybodi, Mortazavian., Sohrabvandi, da Cruz \& Mohammadi, 2017). El tipo de matriz o alimento que sirva de vehículo, será un factor determinante en la supervivencia.

\section{Matrices lácteas vs no lácteas}

La viabilidad de los probióticos se ve comprometida por el ambiente que los rodea. El oxígeno disuelto en el alimento, su pH y la concentración de algunos metabolitos, como los ácidos orgánicos, disminuyen la supervivencia. También influyen la actividad del agua y la presión osmótica del alimento (Costa, Fonteles, de Jesús \& Rodrigues, 2013; Allouche et al., 2018). Está demostrado que los componentes de la leche confieren protección a los probióticos. En particular, las proteínas presentes en el suero (por ejemplo la lactoalbúmina y la lactoglobulina), tienen un efecto amortiguador, que mejora la resistencia de estos microorganismos, cuando son sometidos a ambientes ácidos (Vargas, Olson \& Aryana, 2015). Además, las caseínas de la leche (particularmente las $\beta$ y la $\kappa$ caseína), pueden servir como fuente de nitrógeno para el crecimiento de los probióticos, permitiéndoles mantenerse metabólicamente activos, durante la vida de anaquel del alimento (Yu, Amorim, Marques, Calhau \& Pintado, 2016; Huang et al., 2017).

Verruck et al. (2017) comprobaron que la grasa de la leche de cabra protege a Bifidobacterium BB-12, manteniendo el $94 \%$ de las bacterias viables, después de someterlas a ambientes ácidos. Por otra parte, Ranadheera, Evans, Adams
\& Baines (2013) atribuyeron un efecto protector a la grasa de la leche, para conservar la viabilidad de L. acidophilus LA5, B.animalis subespecie. lactis BB-12, y Propionibacterium jensenii 702 , en helados de chocolate.

Aunque las matrices no-lácteas difieren mucho en composición con respecto a la leche, pueden contener moléculas que estimulen el crecimiento de los probióticos. Este es el caso de los carbohidratos no digeribles (fibras solubles), proteínas y vitaminas, presentes en algunos cereales (Chavan, Gat, Harmalkar \& Waghmare, 2018). Otros compuestos, como los $\beta$-glucanos de la cebada, además de proteger a probióticos como L. plantarum WCFS1, L. acidophilus LA5 y L. johnsonii CECT 289, disminuyen la inflamación intestinal de su hospedero (Arena et al., 2016). También se reportan diversos beneficios cuando la matriz alimentaria contiene fructanos tipo inulina, como aquellos que provienen de la chicoria, o los que son extraídos de los agaves (Chavan, Gat, Harmalkar \& Waghmare, 2018).

La composición y diversidad de alimentos no lácteos a los que se han incorporado probióticos es mucha y cada especie y cepa pueden reaccionar de diferente manera. Por ello, es importante llevar a cabo ensayos de supervivencia con diferentes especies y cepas de probióticos. Lo conveniente es realizarlos en la matriz que se pretenda utilizar para desarrollar un nuevo alimento (Sanders \& Marco, 2010). La temperatura de almacenamiento, la actividad de agua del alimento y el tipo de empaque, también influyen en la supervivencia del probiótico y son factores que por lo tanto, deben contemplarse durante el desarrollo del alimento (Tripathi \& Giri, 2014).

\section{Supervivencia de probióticos en jugos de frutas y vegetales}

Existe gran interés en el desarrollo de jugos de frutas y hortalizas funcionales, que contengan probióticos. La principal razón es la gran aceptación que tiene este tipo de alimentos en poblaciones de todas las edades. Además, las frutas y vegetales contienen carbohidratos que pueden ser utilizados por el microorganismo para su crecimiento. También, antioxidantes, vitaminas y minerales, que mejoran la nutrición del consumidor (Rivera-Espinoza \& GallardoNavarro, 2010). Se pueden utilizar dos estrategias: a) la adición directa de probióticos sin fermentar al jugo y b) la fermentación del jugo con los probióticos.

En la Tabla III se presentan algunos de los jugos con probióticos que ya se encuentran en el mercado. El proceso industrial de jugos no fermentados y fermentados es muy similar. Comprende la producción del jugo por las técnicas tradicionales (lavado, prensado, filtración), el llenado en envases estériles, seguido de un proceso de pasteurización y la posterior adición de los probióticos. Si el jugo no se va a fermentar, se refrigera hasta su consumo. Si se pretende 
Tabla III. Jugos comerciales que contienen probióticos.

\begin{tabular}{|l|l|l|}
\hline \multicolumn{1}{|c|}{ Bebida } & \multicolumn{1}{c|}{ Compañía } & \multicolumn{1}{c|}{ Probiótico } \\
\hline $\begin{array}{l}\text { Jugos de fruta orgánicos combinación de varias } \\
\text { frutas }\end{array}$ & $\begin{array}{l}\text { Garden of Flavor } \\
\text { Ohio, EUA }\end{array}$ & B. coagulans \\
\hline Jugo de fruta & Biola, Noruega & L. rhamnosus \\
\hline Jugo de zanahoria con extracto de jengibre & GoodBelly Colorado, EUA & L. plantarum 299v \\
\hline Jugo de naranja y mango & Valio Bioprofit, Finland & Lb. rhamnosus \\
\hline Jugos de fresa & Proviva EMEA Probi AB, Suecia & L. plantarum 299v \\
\hline Jugo de frutas tropicales, manzana, naranja & Bravo Friscus Probi AB, Suecia & $\begin{array}{l}\text { L. plantarum HEAL9 y } L . \\
\text { paracasei } 8700: 2\end{array}$ \\
\hline $\begin{array}{l}\text { Jugos fermentados de coco-mango, naranja- } \\
\text { zanahoria, kiwi-manzana }\end{array}$ & $\begin{array}{l}\text { Good Morning, Crystal Lily Industry } \\
\text { LTD. China }\end{array}$ & $\begin{array}{l}\text { L. paracasei y } \\
\text { L. thermophilus }\end{array}$ \\
\hline Jugos de ciruela, uva y naranja & $\begin{array}{l}\text { Melee probiotics, Malee Enterprise } \\
\text { Company Ltd., Tailandia }\end{array}$ & L. paracasei \\
\hline Jugos de frutas y vegetales & $\begin{array}{l}\text { Welo Probiotic } \\
\text { Canada }\end{array}$ & B. coagulans \\
\hline
\end{tabular}

Adaptada de Ranadheera, Baines \& Adams (2010).

fermentar se sube y controla la temperatura para promover la fermentación y una vez concluida ésta, el producto se refrigera (Ranadheera, Vidanarachchi, Rocha, Cruz \& Ajlouni, 2017). Un campo de exploración importante para jugos de origen vegetal, es la obtención de productos parcialmente fermentados, que han tenido mucho éxito en el caso de productos lácteos (Ranadheera, Vidanarachchi, Rocha Cruz, \& Ajlouni, 2017).

\section{Supervivencia en jugos sin fermentar}

En lo que se refiere a los jugos sin fermentar, las frutas $\mathrm{y}$ vegetales han sido fuente de aislamiento de numerosas bacterias lácticas del género Lactobacillus, que pudieran añadirse al jugo. Destacan $L$. brevis, $L$. delbrueckii y $L$. plantarum. Sin embargo, el reto tecnológico es alto, debido a los bajos valores de $\mathrm{pH}$ en el medio y a la presencia de oxígeno en la matriz. Estos factores imposibilitan el crecimiento de una gran parte de las especies del género Bifidobacterium (estrictamente anaerobias) y limitan el crecimiento del género Lactobacillus. El pH de la mayoría de los jugos de fruta se encuentra entre 2.5 a 3.7. Esto puede afectar considerablemente a la viabilidad de los lactobacilos. Por ejemplo, el jugo de piña y el de kiwi, disminuyen el crecimiento de L. acidophilus, mientras que el de fresa, inhibe a L. casei (Vinderola, Mocchiutti \& Reinheimer, 2002). No obstante, L. plantarum, L. delbrueckii y L. casei crecen adecuadamente en jugo de durazno inmediatamente después de su procesamiento. Sin embargo, después de almacenar los jugos durante cuatro semanas a $4{ }^{\circ} \mathrm{C}$, las poblaciones de $L$. plantarum y $L$. delbrueckii disminuyen 2 y $3 \log \mathrm{UFC} / \mathrm{mL}$, respectivamente, mientras que $L$. casei, no sobrevive (Pakbin, Razavi, Mahmoudi \& Gajarbeygi, 2014). En general, el efecto depende de la composición de la matriz y la especie y cepa específicos, por lo que deben elegirse especies resistentes a pH bajos (Neffe-Skocińska, Rzepkowska, Szydłowska \& Kołożyn-Krajewska, 2018).

Algunos investigadores proponen mezclar las frutas con leche para que las proteínas de esta última, ejerzan su efecto amortiguador. Otra alternativa es microencapsular a las bacterias, para protegerlas del ambiente ácido. Sin embargo, en este último caso, el tamaño de partícula será crucial (40-100 $\mu \mathrm{m})$ tanto para no afectar la viabilidad del microorganismo, como para no proporcionar un efecto "arenoso" (Champagne, Ross, Saarela, Hansen \& Charalampopoulos, 2011). En general, los probióticos encapsulados adicionados a jugos de frutas, conservan mejor su viabilidad durante el almacenamiento en refrigeración, en comparación con aquellos que se adicionan libres (Neffe-Skocińska, Rzepkowska, Szydłowska \& Kołożyn-Krajewska, 2018).

Otra alternativa para proteger a los probióticos del ambiente adverso de los jugos, es la adición de prebióticos o fibras solubles, como la inulina y sus hidrolizados (fructooligosacáridos, FOS). La adición de FOS a jugo clarificado de manzana, coadyuvó a conservar la viabilidad de L. paracasei subespecie paracasei durante 28 días en refrigeración (Pimentel, Madrona, García \& Prudencio, 2015). En contraste, da Costa et al. (2017), no encontraron un efecto protector de los FOS $(20 \mathrm{~g} / \mathrm{L})$ cuando esta misma especie fue inoculada en jugo de naranja (pH más bajo). Los prebióticos estimulan selectivamente el crecimiento de los probióticos, permitiendo que se sigan reproduciendo durante el almacenamiento del alimento. El término sin-biótico se 
utiliza cuando probióticos y prebióticos son adicionados al mismo tiempo en el alimento. Algunos autores recomiendan encapsular la combinación probiótico-prebiótico (sinbióticos), para mejorar la supervivencia de los probióticos en los jugos (Burgain, Gaiani, Linder \& Scher, 2011).

\section{Supervivencia en jugos fermentados}

La supervivencia de los probióticos en los jugos fermentados depende principalmente de la temperatura de fermentación. Otros factores que pueden influir son el tipo de microorganismo y de fruta o vegetal utilizado (Ranadheera, Vidanarachchi, Rocha, Cruz \& Ajlouni, 2017). En general, los probióticos permanecen estables después de la fermentación. Es decir, la supervivencia, a temperaturas de refrigeración, se mantiene a niveles adecuados para ejercer un efecto benéfico (Ranadheera, Vidanarachchi, Rocha, Cruz \& Ajlouni, 2017). Por ejemplo, Sheehan, Ross \& Fitzgerald, (2007) inocularon L. casei, L. rhamnosus, y L. paracasei en jugos de naranja y piña. Después de 12 semanas de almacenamiento en refrigeración $\left(4-6{ }^{\circ} \mathrm{C}\right)$, observaron supervivencia en el orden de $10^{7} \mathrm{UFC} / \mathrm{mL}$. También se han realizado investigaciones para añadir probióticos a jugos de zanahoria, col, tomate, frutas tropicales de diferentes países y pepino, con buenos niveles de supervivencia (Granato, Branco, Nazzaro, Cruz \& Faria, 2010; Rivera-Espinoza \& Gallardo-Navarro, 2010). Mauro, Guergoletto \& Garcia, (2016) fermentaron jugo de zanahoria y blueberry $(\mathrm{pH}<4.0)$ inoculándolo con $L$. reuteri LR92; en donde las cuentas del probiótico permanecieron en concentraciones de $10^{8} \mathrm{UFC} / \mathrm{mL}$, después de 28 días en refrigeración.

La fermentación de jugos con probióticos puede producir metabolitos que afectan el aroma, el sabor, la textura y la viscosidad del alimento. En Europa se realizó un estudio con panelistas entrenados para evaluar las características sensoriales de jugos de naranja conteniendo Lactobacillus rhamnosus GG. Los jueces detectaron sabores y aromas "a leche", "a medicina", "artificiales" y "a tierra" (Luckow \& Delahunty, 2004). Por tanto, es necesario realizar estudios sensoriales de los prototipos de jugos fermentados con probióticos, antes de lanzarlos al mercado.

Otra alternativa son los purés de frutas o verduras fermentados por probióticos. Tsen, Lin \& King (2004), desarrollaron purés de plátano fermentados por $L$. acidophilus inmovilizado en carrageninas en presencia de fructanos. Estos últimos mejoraron la eficiencia de fermentación y promovieron que las cuentas del probiótico se mantuvieran en el orden de $10^{8}$ $\mathrm{UFC} / \mathrm{g}$. Por su parte, Leuconostoc mesenteroides mantuvo cuentas de $10^{9} \mathrm{UFC} / \mathrm{g}$ después de 14 días de almacenamiento, al ser añadido a puré de pera coreana (Kim, Chae \& In, 2010). La incorporación de L. plantarum 33 también resultó exitosa en pastas de aceituna (Alves et al., 2015).

Se ha observado que después de la fermentación, la viabilidad de los probióticos tiende a estabilizarse. Sin embargo, para protegerlos durante el proceso, también se aplican estrategias como la adición de prebióticos y el encapsulamiento (Ranadheera, Vidanarachchi, Rocha, Cruz \& Ajlouni, 2017). Otra alternativa es utilizar especies reconocidas como seguras, que al esporular, se auto protegen de las condiciones adversas como B. coagulans Bc30.

\section{Bebidas elaboradas con soya, cereales y similares}

Existe una gran cantidad de bebidas fermentadas tradicionales elaboradas ancestralmente a partir de soya, cereales y similares. Éstas, se originaron en diferentes lugares del mundo y siguen consumiéndose en la actualidad. Por ejemplo, bebidas de soya originarias del continente asiático. También, bebidas a base de avena, arroz, trigo, malta, cebada y otros cereales, que se consumen en países europeos y africanos. En México y Latinoamérica destacan aquellas elaboradas a partir de la fermentación del maíz, como el pozol y otras, derivadas de la fermentación del maguey, como el pulque. A partir de este siglo ha aumentado el interés por identificar los consorcios microbianos que fermentan a estas bebidas y la búsqueda de especies con potencial probiótico (Lebaka, Wee, Narala \& Joshi, 2018). En general, se sabe que predominan especies de levaduras (Saccharomyces y no-Saccharomyces), y de bacterias del género Lactobacillus (Ben Omar \& Ampe, 2000). En el caso del pulque, la presencia de Lactobacillus acidophilus y Leuconostoc mesenteroides, es importante para la fermentación (Escalante et al., 2008), lo mismo que L. plantarum, L. fermentum, L. casei, L. delbrueckii y Bifidobacterium minimum, para el pozol (Ben Omar \& Ampe, 2000).

Para poder comercializar estas bebidas ancestrales como vehículos para probióticos, se requieren estudios más profundos (Foligné, Daniel \& Pot, 2013). En el inter, se están haciendo investigaciones para desarrollar nuevas bebidas, e innovar en este campo. La malta resulta uno de los mejores sustratos para el crecimiento de probióticos en productos no fermentados, mientras que la cebada permite el crecimiento de $L$. plantarum, $L$ reuteri y $L$. acidophilus en bebidas con un $\mathrm{pH} \leq 3.0$ (Charalampopoulos, Pandiella \& Webb, 2003). Estos mismos probióticos mantuvieron cuentas de $10^{8} \mathrm{UFC} /$ $\mathrm{mL}$ en bebidas fermentadas a base de cebada, malta o avena, cuando el $\mathrm{pH}$ final se mantiene entre 3.3 y 3.7. Sin embargo, la aceptación por el consumidor es mejor, entre mayor sea el pH de la bebida y más acetaldehído se produzca durante la fermentación (Salmerón, Thomas \& Pandiella, 2015).

La ventaja de la fermentación es ayudar a que sea mejor digerido el cereal, además de que durante el proceso se sintetizan metabolitos con potencial bioactivo (p.e, ácidos grasos de cadena corta). Por otro lado, es importante evaluar la aceptación del consumidor cuando se usan cultivos mixtos, ya que las cuentas microbianas de las diferentes poblaciones 
pueden mantenerse viables. Sin embargo, los metabolitos producidos son diferentes que cuando se usan mezclas individuales. Por ejemplo Rathore, Salmerón \& Pandiella, (2012) observaron que la producción de ácido láctico fue menor al inocular mezclas de L. acidophilus y L. plantarum, en bebidas elaboradas con diferentes cereales, comparada con la producción de este ácido, cuando se inoculó individualmente a los probióticos. No obstante, la supervivencia de los microorganismos fue similar, en ambas condiciones.

Algunos desarrollos interesantes contemplan la preparación de bebidas sin-bióticas a base de prebióticos (inulina $\mathrm{o}$ fructooligosacáridos) y probióticos, utilizando mezclas de cereales. Por ejemplo, Bianchi, Rossi, Gomes \& Sivier (2015) prepararon bebidas de soya y quinoa inoculadas con L. casei LC-1 conteniendo fructooligosacáridos. Las cuentas microbianas del probiótico permanecieron en $10^{8} \mathrm{UFC} / \mathrm{mL}$ durante 28 días. Sin embargo, a medida que aumentó el tiempo de almacenamiento, se observó un aumento en la viscosidad de las bebidas. Éste, fue proporcional al contenido de quinoa, factor que posiblemente influyó en la aceptación del producto, ya que el más aceptado fue el que contenía menos quinoa (70\% soya, $30 \%$ quinoa).

Actualmente, la compañía japonesa Grain-Drops comercializa con éxito bebidas probióticas a base de una mezcla de cereales (arroz, avena, quinoa, amaranto), inulina y cultivos de $B$. bifidum, L. acidophilus, L. casei, L. bulgaricus, L. rhamnosus, $B$. lactis y $S$. thermophilus con sabor natural blue berry y mango-jengibre.

En general, la supervivencia de los probióticos en productos fermentados es mayor cuando la fermentación se lleva a cabo de 37 a $43{ }^{\circ} \mathrm{C}$. Además, depende de la resistencia del probiótico a los metabolitos que se generan, principalmente ácido láctico y al oxígeno producido durante el proceso. Por tanto, deben usarse especies resistentes al ácido y al oxígeno (Salmerón, Thomas \& Pandiella, 2015).

\section{SUPERVIVENCIA DE PROBIÓticos EN OTROS PRODUCTOS DE ORIGEN VEGETAL Productos en polvo}

El interés por utilizar a los productos vegetales como vehículo de probióticos se extiende al desarrollo de polvos para la preparación de bebidas. Entre sus ventajas se encuentran la de ocupar menor espacio al envasarse, tener una vida de anaquel más larga y una actividad de agua (Aw), más propicia para la sobrevivencia de los probióticos (Burgain, Gaiani, Linder \& Scher, 2011). Borges et al. (2016) estudiaron el efecto del calor sobre la viabilidad de L. plantarum 299v, en la producción de polvos deshidratados a partir de fresa plátano y manzana. Probaron dos metodologías; primero dejaron que el probiótico se adhiriera a los frutos y posteriormente los secaron por convección con aire caliente en un secador de charolas $\left(40^{\circ} \mathrm{C}\right.$;
$1.5 \mathrm{~m} / \mathrm{s} ; 24-48 \mathrm{~h}$ ), posteriormente molieron los frutos secos y los almacenaron $\left(4^{\circ} \mathrm{C}\right.$ y $\mathrm{T}$ ambiente $)$, durante tres meses. El segundo proceso, que fue el más efectivo; consistió en secar los frutos como ya se describió y secar una suspensión del microorganismo por aspersión $\left(75^{\circ} \mathrm{C}\right.$, entrada, $200^{\circ} \mathrm{C}$, salida), para después adicionarlo a los polvos de fruta. La supervivencia de la bacteria al utilizar el primer método, dependió del tipo de fruta y de la temperatura de almacenamiento, siendo mayor en los polvos de fresa y en los polvos almacenados a $4{ }^{\circ} \mathrm{C}$. En contraste, L. plantarum $299 \mathrm{v}$ presentó cuentas de $10^{8}$ $10^{9} \mathrm{UFC} / \mathrm{g}$ al ser incorporado por el segundo método a los polvos de frutas, presentando una mayor estabilidad durante el almacenamiento a temperatura ambiente.

Estos resultados confirman el cuidado que hay que tener durante la planeación del proceso de incorporación del probiótico. Además del tipo, temperatura y tiempo de secado, debe considerarse el método para añadir el probiótico en el alimento, que garantice menores pérdidas. Por ejemplo, embeber la fruta con la suspensión de la bacteria puede causar pérdida del microorganismo, ya que parte de la suspensión queda en las charolas. En cambio, la pérdida puede ser menor, al mezclar el polvo de fruta, con el microorganismo previamente deshidratado. Al deshidratarlo, hay que considerar la mejor estrategia para protegerlo del calor. Entre estas se encuentran: a) añadir sólidos de leche desgrasada o de proteínas de suero lácteo, b) añadir carbohidratos complejos como inulina, quitosano, carbohidratos de maíz, almidones resistentes o $\beta$-glucanos y c) encapsular al microorganismo con diferentes matrices comestibles como pectina, alginatos, proteínas de diferentes orígenes, etc. (Fu, Huang, Xiao \& Chen, 2018).

\section{Frutas y vegetales impregnadas con probióticos}

Como se indicó con anterioridad, la supervivencia de los probióticos está relacionada con el tipo de matriz alimentaria que quiera utilizarse como vehículo y con la especie y cepa de microorganismo a utilizar. Por tanto, deben realizarse estudios para cada microorganismo específico y cada matriz alimentaria que se pretenda usar como vehículo. Un factor importante es el grado de maduración del fruto o vegetal, el cual tendrá que ser uniforme (Rascón et al., 2018).

El enriquecimiento de frutas y vegetales con probióticos, se consigue sumergiendo el producto de interés durante 2-10 min en: a) jugo de la misma fruta, b) soluciones amortiguadoras o c) soluciones isotónicas, conteniendo altas concentraciones $\left(10^{9}-10^{10} \mathrm{UFC} / \mathrm{mL}\right)$ del probiótico de elección (Russo et al., 2014). La impregnación resulta más efectiva cuando el alimento se corta en cubos, rodajas o rebanadas debido a que aumenta el área de exposición (Betoret et al., 2003). Una vez impregnado, el fruto puede envasarse fresco (mínimamente procesado) o deshidratarse, a fin de disminuir la Aw del alimento. Russo et al. (2014) impregnaron rodajas de piña 
fresca con L. plantarum o L. fermentum contenidos en amortiguador de citrato de sodio-ácido cítrico ( $\mathrm{pH} 3.8)$. Las rodajas se conservaron en refrigeración $\left(8\right.$ días, $\left.5^{\circ} \mathrm{C}\right)$, como producto mínimamente procesado, presentando cuentas finales entre $2 \times 10^{6}$ y $2 \times 10^{7} \mathrm{UFC} / \mathrm{g}$. Betoret et al. (2003) impregnaron cilindros de manzana $(40 \times 18 \mathrm{~mm})$ con jugo de la misma fruta conteniendo $10^{9} \mathrm{UFC} / \mathrm{mL}$ de L. casei. Las frutas impregnadas contuvieron $10^{7} \mathrm{UFC} / \mathrm{g}$. Posteriormente las deshidrataron por convección en aire caliente $\left(40{ }^{\circ} \mathrm{C}, 4 \mathrm{~m} / \mathrm{s}, 0.037 \mathrm{~kg}\right.$ agua/ $\mathrm{kg}$ materia seca). La sobrevivencia del probiótico dependió del tiempo y temperatura de almacenamiento, presentando cuentas finales de $6.28 \times 10^{5} \mathrm{UFC} / \mathrm{g}$, después de rehidratar el fruto.

Una manera de mejorar la cantidad de microorganismos impregnados es aplicar pulsos de vacío durante la inmersión del alimento. Además, para mejorar la supervivencia, deshidratar por liofilización, en vez de con aire caliente (Betoret et al., 2003; Rascón et al., 2018). Otra metodología que gana interés en la impregnación de probióticos es la deshidratación osmótica. Consiste en sumergir al alimento en una solución hipertónica que contiene al microorganismo. El agua migra del alimento a la solución deshidratándolo parcialmente y los solutos, incluidos los probióticos, migran hacia el alimento (Rascón et al., 2018). El proceso ha resultado exitoso en plátano impregnado con L. rhamnosus conservando niveles de $10{ }^{7} \mathrm{UFC} / \mathrm{g}$ (Huerta Vera et al., 2017). Sin embargo, una de las etapas críticas es el almacenamiento del alimento, donde se observa una pérdida considerable de la viabilidad de los probióticos. Por tanto, es importante determinar la actividad de agua más adecuada para garantizar la supervivencia del microorganismo. Utilizando soluciones hipertónicas de sacarosa de 50\% p/p, Rascón et al. (2018), impregnaron L. rhamnosus en rodajas de plátano por deshidratación osmótica, para posteriormente liofilizarlas. La cinética de supervivencia del microorganismo, demostró que su viabilidad disminuye significativamente, cuando la Aw supera valores de 0.327 . Lo anterior nos indica la importancia de realizar este tipo de cinéticas durante el desarrollo del producto y la de protegerlo contra la humedad, durante su almacenamiento.

\section{Cereales y productos de panadería}

El aumento en el consumo de granos enteros es una buena oportunidad para utilizarlos como vehículos para probióticos, debido a su contenido de carbohidratos complejos, antioxidantes, fitoquímicos y otros compuestos bioactivos (Rivera-Espinoza \& Gallardo-Navarro, 2010). Los carbohidratos complejos (arabinoxilanos, $\beta$ glucanos, fructanos, almidones resistentes) sirven de fuente de carbono a los probióticos, aumentando con ello, sus posibilidades de supervivencia (Kolacek et al., 2017). Como ya se indicó, estos granos pueden fermentarse con probióticos para producir bebidas.
Otra posibilidad es incorporar los probióticos en cereales para desayuno, barras de cereales, galletas y pan. Existen diferentes cereales comerciales en los mercados europeos y estadounidenses, que contienen probióticos. Por ejemplo, las compañías Nestlé ${ }^{\circledR}$, Gerber ${ }^{\circledR}$ y Happy Baby ${ }^{\circledR}$ comercializan cereales de avena conteniendo Bifidobacterium lactis. Kellogg's ${ }^{\circledR}$ tiene a la venta una variedad de su cereal Special $K \circledR$, que también contiene probióticos, incorporados en piezas de yogurt. Otros productos que contienen probióticos son Weetaflakes ${ }^{\circledR}$, cereal de trigo entero que se comercializa en Francia; Muesli ${ }^{\circledR}$, mezcla de cereales que se comercializa en Portugal y las barras de cereales Goodness ${ }^{\circledR}$ y CornyActiv ${ }^{\circledR}$ que se venden en Gran Bretaña y Alemania, respectivamente. Algunos de estos productos indican una vida de anaquel entre los 6 y 12 meses. Sería interesante determinar la viabilidad de los probióticos durante este tiempo. El control de la Aw y la temperatura (en el caso de los cereales que requieren calentamiento), serán los principales factores que afecten la supervivencia (Martins et al., 2013). El microencapsulamiento y la inmovilización en carbohidratos complejos son dos de las estrategias que se utilizan para preservar la viabilidad de los probióticos añadidos a estos productos (Burgain, Gaiani, Linder \& Scher, 2011).

La incorporación de probióticos en pan y otros productos horneados (pizzas, muffins, galletas, pastelillos) resulta de gran interés debido a que son alimentos económicos, consumidos por las poblaciones de todo el mundo. Sin embargo, representa un reto tecnológico debido a las temperaturas de cocimiento y a la pérdida de viabilidad que ocurre al almacenar estos productos a temperatura ambiente. El encapsulamiento de Lactobacillus acidophilus en almidón, conservó cuentas de $10^{8}$ UFC/pan (30- $60 \%$ de sobrevivencia) después de la cocción a $180{ }^{\circ} \mathrm{C}$ durante $16 \mathrm{~min}$. (Altamirano-Fortoul, MorenoTerrazas, Quezada-Gallo \& Rosell, 2012). Sin embargo, el tamaño de las cápsulas puede afectar las características sensoriales del producto, impartiendo una textura granulosa. Otro problema es que las partículas cambian la consistencia de la costra del pan y su color característico (Soukoulis, Yonekura, Gan, Behboudi-Jobbehdar, Parmenter \& Fisk, 2014a). Una alternativa innovadora es la inmovilización de los probióticos en películas o recubrimientos comestibles, otra, la impresión en tercera dimensión (3D) (Zhang, Lou \& Schutyser, 2018).

\section{Recubrimientos comestibles}

Las películas o recubrimientos comestibles son capas delgadas elaboradas a partir de ingredientes grado alimenticio que recubren a un alimento, creando una barrera con el medio ambiente que lo rodea. Se han utilizado principalmente para aumentar la vida de anaquel de productos frescos mínimamente procesados o para incorporar bioactivos que sean liberados controladamente en los alimentos (Pavli, Argyri, Nychas, 
Tassou \& Chorianopoulos, 2018). Entre las ventajas de estos recubrimientos se encuentran las de servir como barrera que controla la transferencia de humedad, y protege contra la oxidación de lípidos. Además, se ha observado que confieren termorresistencia a los microorganismos que se inmovilizan en ellas (Soukoulis, Yonekura, Gan, Behboudi-Jobbehdar, Parmenter \& Fisk, 2014a). Es por ello que actualmente se estudian como vehículos de probióticos en productos de panadería. Estos recubrimientos se dividen en tres grupos de acuerdo a su composición: a) hidrocoloides compuestos por proteínas o carbohidratos, b) lípidos, constituidos por acilgliceroles, ácidos grasos o ceras y c) compuestos, que son una combinación de los dos primeros. Cuando se usan hidrocoloides es conveniente añadir un plastificante para impartir flexibilidad al recubrimiento. Los plastificantes más utilizados son, manitol, glicerol, polietilenglicol y sacarosa, aunque también pueden utilizarse monoglicéridos, ácidos grasos y fructooligosacáridos (Romano, Tavera-Quiroz, Bertola, Mobili, Pinotti \& Gomez-Zavaglia, 2014; Pavli, Argyri, Nychas, Tassou \& Chorianopoulos, 2018).

Las primeras películas que contuvieron probióticos (B. lactis B12) fueron desarrolladas a partir de gelanos o de alginatos, para recubrir trozos de papaya o de manzana. En el caso de las frutas recubiertas con gelanos, las cuentas microbianas permanecieron en $10^{6} \mathrm{UFC} / \mathrm{g}$ durante 10 días, en condiciones de refrigeración (Rojas-Grau, Soliva- Fortuny \& Martin-Belloso, 2009). Otros estudios fueron exitosos al aplicar recubrimientos de gelatina conteniendo $B$. bifidum a la superficie a diferentes tipos de pescado (López de Lacey, López-Caballero, GómezEstaca, Gómez-Guillén \& Montero, 2012).

Los estudios en productos de panadería son más escasos. Soukoulis, Behboudi-Jobbehdar, Yonekura, Parmenter \& Fisk (2014b) recubrieron L. rhamnosus GG con alginato de sodio o con una mezcla de alginato de sodio y proteínas de suero lácteo. Los recubrimientos fueron aplicados a la superficie de panes cocidos, añadiendo un proceso de secado a $60{ }^{\circ} \mathrm{C}$ durante $10 \mathrm{~min}$, para promover la formación de la película, la cual no afectó el sabor, la textura, ni la apariencia de la costra del pan. La supervivencia fue mayor en presencia de proteínas de suero lácteos. Los resultados indicaron que una rebanada de $30-40 \mathrm{~g}$ de pan contenía hasta $6 \times 10^{9}$ UFC viables y una reducción de 1 a 2 ciclos logarítmicos, después de simular condiciones gastrointestinales. Sin embargo, las cuentas viables disminuyeron a $10^{4}$ UFC después del primer día de almacenamiento a temperatura ambiente. Este mismo grupo de investigadores probó diferentes tipos de recubrimientos con base en polisacáridos, a fin de mejorar la supervivencia durante la vida de anaquel del alimento (25 días) a 4 y $25{ }^{\circ} \mathrm{C}$. La sobrevivencia en orden decreciente fue la siguiente: recubrimientos de $\kappa$ carragenina-locus bean $>$ alginato de alta viscosidad $>$ gelatina $>$ alginato de baja viscosidad $=$ pectina de bajo metoxilo. La adición de proteínas de suero lácteo mejoró la sobrevivencia de 1.8 a 6.5 veces a $4{ }^{\circ} \mathrm{C}$ y de 1.6 a 4.3 veces a $25{ }^{\circ} \mathrm{C}$. La presencia de las proteínas de la leche mejoró la adhesión y el recubrimiento de las bacterias, reduciendo el daño osmótico (Soukoulis, Singh, Macnaughtan, Parmenter \& Fisk , 2016).

El uso de películas o recubrimientos comestibles es una estrategia prometedora para desarrollar nuevos productos y preservar la viabilidad de los probióticos, aumentando su capacidad de dispersión en el alimento. Además, preserva la capacidad de los probióticos de producir bacteriocinas, inhibiendo el crecimiento de patógenos importantes como Listeria monocytogenes y permite la incorporación de otros bioactivos, con el fin de aumentar el efecto benéfico que el consumo del alimento al que se incorporan, puede producir en la salud (Pavli, Argyri, Nychas, Tassou \& Chorianopoulos, 2018). Sin embargo, aún se requieren estudios para encontrar las condiciones más adecuadas para preservar la viabilidad del probiótico durante la vida de anaquel del alimento.

\section{Impresión en tercera dimensión}

Una innovación más reciente para incorporar probióticos a los productos de panadería es la impresión en 3D (Zhang, Lou \& Schutyser, 2018). La sobrevivencia de los probióticos durante la cocción depende de la temperatura y tiempo utilizados y del contenido acuoso de la masa, encontrándose que los probióticos resisten mejor la temperatura cuando la humedad de la masa es menor (Zhang, Taal, Boom, Chen, \& Schutyser, 2018). Se plantea la hipótesis de que si hay un aumento en la relación superficie/volumen del producto panadero, la deshidratación del alimento será mucho más rápida durante la cocción y por tanto, habrá una mayor sobrevivencia del probiótico incorporado (Zhang, Lou \& Schutyser, 2018). Este aumento en la relación superficie/volumen puede lograrse mediante impresión 3D.

Zhang, Lou \& Schutyser (2018) estudiaron múltiples formulaciones de masas para panadería combinando tipos de harina, relación harina/agua y adición de aditivos. Además, probando diferentes condiciones de impresión (imagen-forma, tipo de aguja para extruir la pasta, tamaño de figura impresa), para incorporar Lactobacillus plantarum WCFS1 $\left(10^{9} \mathrm{UFC} / \mathrm{g}\right)$ a masas de panadería. Estas masas se imprimieron por extrusión y cocieron a diferentes tiempos y temperaturas, establecidos con base en alcanzar $98 \%$ de la gelatinización del almidón en la masa. Las mejores características reológicas se obtuvieron al utilizar harinas con bajo contenido de proteína (7.2\%), un diámetro de aguja de extrusión de $1.2 \mathrm{~mm}$ y añadiendo $3 \%$ de caseinato de sodio como aditivo para mejorar la red establecida por el gluten. Después de una cocción de $8 \min$ a $145^{\circ} \mathrm{C}$ o $4 \min$ a $175^{\circ} \mathrm{C}$ o $205^{\circ} \mathrm{C}$, la viabilidad del L. plantarum WCFS1 disminuyó 4 log, observándose cuentas de $10^{5} \mathrm{UFC} / \mathrm{g}$ independientemente del tratamiento utilizado. 
A pesar de que estas cuentas están por debajo de las concentraciones recomendadas, la impresión 3D es una alternativa prometedora para utilizar productos de panificación como vehículo de probióticos. Entre las alternativas propuestas para mejorar la supervivencia de los probióticos en impresiones 3D se encuentran: a) inmovilizar o encapsular los probióticos en diferentes matrices antes de incorporarlos a la masa, b) buscar una estructura de impresión con mayor área de exposición superficie/volumen y c) combinar otras tecnologías como las microondas para reducir el tiempo de cocción.

\section{Conclusiones}

El uso de matrices no lácteas como vehículo de probióticos es un campo prometedor para la industria alimentaria que puede beneficiar tanto al consumidor común, como a grupos específicos que presentan alergias a la leche o prefieren un consumo vegano. Otras poblaciones importantes pueden ser los niños y ancianos. Sin embargo, hace falta investigación en diversos campos, para desarrollar productos exitosos, tanto en su aceptación como en su funcionalidad, entendiendo ésta como la promoción de un efecto benéfico en la salud. Es necesario entender mejor los cambios fisiológicos de los probióticos sometidos a diferentes condiciones de estrés asociados con matrices de origen vegetal; cómo responden (sensorial tecnológica y funcionalmente) y si sobreviven los probióticos en una o en la combinación de varias matrices de origen vegetal. También es importante mejorar el conocimiento sobre los materiales y tecnologías más adecuadas (p.e microencapsulamiento, inmovilización en cubiertas comestibles, impresión 3D) para proteger a los probióticos y realizar estudios de calidad que garanticen la estabilidad del probiótico durante su vida de anaquel y su efecto benéfico en la salud, sin olvidar la imperiosa necesidad de contar con una legislación apropiada para su uso en alimentos. La atención a la resolución de estas necesidades contribuirá positivamente al éxito de los alimentos probióticos no lácteos, un campo muy atractivo tanto para la industria alimentaria, como para el consumidor con necesidades especiales o de aquel que busca alternativas saludables para su alimentación.

\section{Agradecimientos}

Los autores agradecen al Consejo Nacional de Ciencia y Tecnología (CONACYT) por la beca a la estudiante de maestría Valeria Castillo Escandón.

\section{REFERENCIAS}

Aguilar-Toalá, J. E., García-Varela, R., García, H. S., MataHaro, V., González-Córdova, A. F., Vallejo-Córdoba, B. \& Hernández-Mendoza, A. (2018). Postbiotics: An evolving term within the functional foods field. Trends in Food Science \& Technology, 75, 105-114. DOI: 10.1016/j. tifs.2018.03.009

Allouche, R., Dupont, S., Charriau, A., Gervais, P., Beney, L. \& Chambin, O. (2018). Optimized tableting for extremely oxygen-sensitive probiotics using direct compression. International Journal of Pharmaceutics, 538(1), 14-20. DOI: 10.1016/j.ijpharm.2018.01.010

Altamirano-Fortoul, R., Moreno-Terrazas, R., Quezada-Gallo, A. \& Rosell, C. M. (2012). Viability of some probiotic coatings in bread and its effect on the crust mechanical properties. Food Hydrocolloids, 29(1), 166-174. DOI: 10.1016/j.foodhyd.2012.02.015

Alves, M., Peres, C. M., Hernández-Mendonza, A., Bronze, M. R., Peres, C. \& Malcata, F. X. (2015). Olive paste as vehicle for delivery of potential probiotic Lactobacillus plantarum 33. Food Research International, 75, 61-70. DOI:10.1016/j.foodres.2015.04.048

Arena, M. P., Russo, P., Capozzi, V., Rascón, A., Felis, G. E., Spano, G. \& Fiocco, D. (2016). Combinations of cereal $\beta$-glucans and probiotics can enhance the antiinflammatory activity on host cells by a synergistic effect. Journal of Functional Foods, 23, 12-23. DOI:10.1016/j. jff.2016.02.015

Augustin, M. A. \& Sanguansri, L. (2015). Challenges and solutions to incorporation of nutraceuticals in foods. Annual Review of Food Science and Technology, 6, 463477. DOI:10.1146/annurev-food-022814-015507

Bagon, B. B., Valeriano, V. D. V., Oh, J. K., Pajarillo, E. A. B., Cho, C.-S. \& Kang, D.-K. (2018). Comparative exoproteome analyses of Lactobacillus spp. reveals species- and strainspecific proteins involved in their extracellular interaction and probiotic potential. $L W T, \mathbf{9 3}, 420-426$. DOI:10.1016/j. lwt.2018.03.069

Begum, A. A., Jakaria, D. M., Anisuzzaman, S. M., Islam, M. \& Mahmud, S. A. (2015). Market assessment and product evaluation of probiotic containing dietary supplements available in Bangladesh market. Journal of Pharmaceutics, 2015, 763796. DOI:10.1155/2015/763796

Ben Omar, N. \& Ampe, F. (2000). Microbial community dynamics during production of the Mexican fermented maize dough pozol. Applied and Environmental Microbiology, 66(9), 3664-3673. DOI:10.1128/aem.66.9.3664-3673.2000

Betoret, N., Puente, L., Díaz, M. J., Pagán, M. J., García, M. J., Gras, M. L., Martínez-Monzó, J. \& Fito, P. (2003). Development of probiotic-enriched dried fruits by vacuum impregnation. Journal of Food Engineering, 56(2), 273277. DOI:10.1016/S0260-8774(02)00268-6

Bianchi, F., Rossi, E. A., Gomes, R. G. \& Sivieri, K. (2015). Potentially synbiotic fermented beverage with aqueous extracts of quinoa (Chenopodium quinoa Willd) and soy. Food Sci. Technol. Int., 21(6), 403-415. DOI:10.1177/1082013214540672

Borges, S., Barbosa, J., Silva, J., Gomes, A. M., Pintado, M., Silva, C. L. M., Morais, A. \& Teixeira, P. (2016). A feasibility study of Lactobacillus plantarum in fruit powders after processing and storage. International Journal of Food Science \& Technology, 51(2), 381-388. DOI:10.1111/ ijfs. 12975 
Burgain, J., Gaiani, C., Linder, M. \& Scher, J. (2011). Encapsulation of probiotic living cells: From laboratory scale to industrial applications. Journal of Food Engineering, 104(4), 467483. DOI:10.1016/j.jfoodeng.2010.12.031

Champagne, C. P., Ross, R. P., Saarela, M., Hansen, K. F. \& Charalampopoulos, D. (2011). Recommendations for the viability assessment of probiotics as concentrated cultures and in food matrices. International Journal of Food Microbiology, 149(3), 185-193. DOI:10.1016/j. ijfoodmicro.2011.07.005

Charalampopoulos, D., Pandiella, S. S. \& Webb, C. (2003). Evaluation of the effect of malt, wheat and barley extracts on the viability of potentially probiotic lactic acid bacteria under acidic conditions. International Journal of Food Microbiology, 82(2), 133-141. DOI:10.1016/S01681605(02)00248-9

Chavan, M., Gat, Y., Harmalkar, M. \& Waghmare, R. (2018). Development of non-dairy fermented probiotic drink based on germinated and ungerminated cereals and legume. LWT, 91, 339-344. DOI:10.1016/j.lwt.2018.01.070

Costa, M. G. M., Fonteles, T. V., de Jesus, A. L. T. \& Rodrigues, S. (2013). Sonicated pineapple juice as substrate for $L$. casei cultivation for probiotic beverage development: Process optimization and product stability. Food Chemistry, 139(1), 261-266. DOI: 10.1016/j. foodchem.2013.01.059

Cutting, S. M. (2011). Bacillus probiotics. Food Microbiology, 28(2), 214-220. DOI: 10.1016/j.fm.2010.03.007

da Costa, G. M., de Carvalho Silva, J. V., Mingotti, J. D., Barão, C. E., Klososki, S. J. \& Pimentel, T. C. (2017). Effect of ascorbic acid or oligofructose supplementation on L. paracasei viability, physicochemical characteristics and acceptance of probiotic orange juice. $L W T, \mathbf{7 5}, 195$ 201. DOI:10.1016/j.lwt.2016.08.051

de Simone, C. (2018). The Unregulated Probiotic Market. Clinical Gastroenterology and Hepatology. DOI:10.1016/j. cgh.2018.01.018

Dey, G. (2018). Non-dairy Probiotic Foods: Innovations and market trends. In S. K. Panda \& P. H. Shetty (Eds.), Innovations in technologies for fermented food and beverage industries (pp. 159-173). Springer International Publishing.DOI:10.1007/978-3-319-74820-7_9

Endres, J. R., Clewell, A., Jade, K. A., Farber, T., Hauswirth, J. \& Schauss, A. G. (2009). Safety assessment of a proprietary preparation of a novel Probiotic, Bacillus coagulans, as a food ingredient. Food and Chemical Toxicology, 47(6), 1231-1238. DOI: 10.1016/j.fct.2009.02.018

Endres, J. R., Qureshi, I., Farber, T., Hauswirth, J., Hirka, G., Pasics, I. \& Schauss, A. G. (2011). One-year chronic oral toxicity with combined reproduction toxicity study of a novel probiotic, Bacillus coagulans, as a food ingredient. Food and Chemical Toxicology, 49(5), 1174-1182. DOI:10.1016/j.fct.2011.02.012

Escalante, A., Giles-Gómez, M., Hernández, G., Córdova-Aguilar,
M. S., López-Munguía, A., Gosset, G. \& Bolívar, F. (2008). Analysis of bacterial community during the fermentation of pulque, a traditional Mexican alcoholic beverage, using a polyphasic approach. International Journal of Food Microbiology, 124(2), 126-134. DOI:10.1016/j. ijfoodmicro.2008.03.003

Euromonitor, 2015. Global and regional trends of the probiotics and omega fatty acids market china international Probiotic and Omega-3 industry summit. Recuperado de https:// www.uschinahpa.org/wp-content/uploads /2015 /07 / EMI-US-China-HPA-Probiotics- and-Omega-2015-Final. pdf

FAO/WHO.(2006). Probióticos en los alimentos. Propiedades saludables y nutricionales y directrices para la evaluación. Roma: Estudio FAO Alimentación y Nutrición 85.

FAO/WHO (2001). Evaluation of health and nutritional properties of powder milk and live lactic acid bacteria.Recuperado de http://www.who.int/foodsafety/publications/fs management/en/probiotics.

Feldman, M. 2015. The probiotics market in the Americas: from Canada to Chile. Euromonitor International Network. Recuperado de https:/www.probiotaamericas.com/wpcontent/uploads/2015/06/Monica-Feldman-EuromonitorProbiota-Americas.pdf

Fitzpatrick, L. R., Small, J. S., Greene, W., Karpa, K. \& Keller, D. (2012). Sa2053 Bacillus coagulans Bc30 limits the recurrence of Clostridium difficile-induced colitis following vancomycin withdrawal in mice. Gastroenterology, 142(5, Supplement 1), S-390. DOI:10.1016/S0016-5085(12)61479-6

Foligné, B., Daniel, C. \& Pot, B. (2013). Probiotics from research to market: the possibilities, risks and challenges. Current Opinion in Microbiology, 16(3), 284-292. DOI:10.1016/j. mib.2013.06.008

Fredua-Agyeman, M., Parab, S. \& Gaisford, S. (2016). Evaluation of commercial probiotic products. British Journal of Pharmacy, 1, 84-89. DOI:10.5920/bjpharm.2016.11

Fu, N., Huang, S., Xiao, J. \& Chen, X. D. (2018). Producing powders containing active dry probiotics with the aid of spray drying. In F. Toldrá (Ed.), Advances in Food and Nutrition Research (pp. 211-262): Academic Press.DOI: 10.1016/bs.afnr.2018.02.003

Granato, D., Branco, G. F., Nazzaro, F., Cruz, A. G. \& Faria, J. A. F. (2010). Functional foods and nondairy probiotic food development: trends, concepts, and products. Comprehensive Reviews in Food Science and Food Safety, 9(3), 292-302. DOI:10.1111/j.1541-4337.2010.00110.x

Hill, C., Guarner, F., Reid, G., Gibson, G. R., Merenstein, D. J., Pot, B., Morelli, L., Canani, R. B., Flint, H.J., Salminen, S., Calder, P.C. \& Sanders, M. E. (2014). Expert consensus document. The International Scientific Association for Probiotics and Prebiotics consensus statement on the scope and appropriate use of the term probiotic. Nature ReviewsGastroenterology andHepatology, 11(8), 506- 
514. DOI: $10.1038 /$ nrgastro.2014.66

Hoffman, F. A. (2008). Business considerations in the development of probiotics. Clinical Infectious Diseases, 46 (S2), S141-S143. DOI:10.1086/523323

Huang, S., Méjean, S., Rabah, H., Dolivet, A., Le Loir, Y., Chen, X. D., Jan, G., Jeantet, R. \& Schuck, P. (2017). Double use of concentrated sweet whey for growth and spray drying of probiotics: Towards maximal viability in pilot scale spray dryer. Journal of Food Engineering, 196, 11-17. DOI:10.1016/j.jfoodeng.2016.10.017

Huerta-Vera, K., Flores-Andrade, E., Pérez-Sato, J. A., MoralesRamos, V., Pascual-Pineda, L. A. \& Contreras-Oliva, A. (2017). Enrichment of banana with Lactobacillus rhamnosususing double emulsion and osmotic dehydration. Food and Bioprocess Technology, 10(6), 1053-1062. DOI:10.1007/s11947-017-1879-2

Hui, S (2015). Global and regional trends of the probiotics and omega fatty acids market. Recuperado de http:// uschinahpa.org/wp-content/uploads/2015/07/EMI-USChina-HPA-Probiotic-and-Omega-2015-Final.pdf

Hun, L. (2009). Bacillus coagulans significantly improved abdominal pain and bloating in patients with IBS. Postgraduate Medicine, 121(2), 119-124. DOI:10.3810/ pgm.2009.03.1984

Kapse, N. G., Engineer, A. S., Gowdaman, V., Wagh, S. \& Dhakephalkar, P. K. (2018). Functional annotation of the genome unravels probiotic potential of Bacillus coagulans HS243. Genomics. DOI:10.1016/j.ygeno.2018.05.022

Kechagia, M., Basoulis, D., Konstantopoulou, S., Dimitriadi, D., Gyftopoulou, K., Skarmoutsou, N. \& Fakiri, E. M. (2013). Health benefits of probiotics: A review. ISRN Nutrition, 2013, 481651.DOI:10.5402/2013/481651

Kim, D. C., Chae, H. J. \& In, M.-J. (2010). Fermentation characteristics of Korean pear (Pyrus pyrifolia Nakai) puree by the Leuconostoc mesenteroides 51-3 strain isolated from Kimchi. African Journal of Biotechnology, 9(35), 5735-5738.

Kolacek, S., Hojsak, I., Berni Canani, R., Guarino, A., Indrio, F., Orel, R., Pot, B., Shamir, R., Szajewska, H., Vandenplas, Y., van Goudoever, J. \& Weizman, Z. (2017). Commercial probiotic products: A call for improved quality control. A position paper by the ESPGHAN working group for probiotics and prebiotics. Journal of Pediatric Gastroenterology and Nutrition, 65(1), 117-124. DOI:10.1097/mpg.0000000000001603

Lahtinen, S. J. (2012). Probiotic viability - does it matter? Microbial Ecology in Health and Disease, 23, 10.3402/ mehd.v3423i3400.18567. DOI:10.3402/mehd.v23i0.18567

Lebaka, V. R., Wee, Y. J., Narala, V. R. \& Joshi, V. K. (2018). Development of New Probiotic Foods-A Case Study on Probiotic Juices. In A. M. Grumezescu \& A. M. Holban (Eds.), Therapeutic, Probiotic, and Unconventional Foods (pp. 55-78): Academic Press. DOI:10.1016/B978-0-12814625-5.00004-2
López de Lacey, A. M., López-Caballero, M. E., Gómez-Estaca, J., Gómez-Guillén, M. C. \& Montero, P. (2012). Functionality of Lactobacillus acidophilus and Bifidobacterium bifidum incorporated to edible coatings and films. Innovative Food Science \& Emerging Technologies, 16, 277-282. DOI:10.1016/j.ifset.2012.07.001

Luckow, T. \& Delahunty, C. (2004). Consumer acceptance of orange juice containing functional ingredients. Food Research International, 37(8), 805-814. DOI:10.1016/j. foodres.2004.04.003

Martins, E. M. F., Ramos, A. M., Vanzela, E. S. L., Stringheta, P. C., de Oliveira Pinto, C. L. \& Martins, J. M. (2013). Products of vegetable origin: A new alternative for the consumption of probiotic bacteria. Food Research International, 51(2), 764-770. DOI:10.1016/j.foodres.2013.01.047

Mauro, C., Guergoletto, K. \& Garcia, S. (2016). Development of blueberry and carrot juice blend fermented by Lactobacillus reuteri LR92. Beverages, 2(4), 1-11. DOI:10.3390/beverages 2040037

McFarland, L. V., Evans, C. T. \& Goldstein, E. J. C. (2018). Strain-specificity and disease-specificity of probiotic efficacy: A systematic review and meta-analysis. Frontiers in Medicine, 5, 124. DOI:10.3389/fmed.2018.00124

Meybodi, N., Mortazavian, A. M., Sohrabvandi, S., G da Cruz, A. \& Mohammadi, R. (2017). Probiotic supplements and food products: Comparison for different targets. Applied Food Biotechnology, 4(3), 10. DOI:10.22037/afb.v4i3.16420

Min, M., Bunt, C. R., Mason, S. L. \& Hussain, M. A. (2018). Non-dairy probiotic food products: An emerging group of functional foods. CriticalReviews in Food Science and Nutrition, 9, 1-16. DOI:10.1080/10408398.2018.1462760

Morelli, L. (2007). In vitro assessment of probiotic bacteria: From survival to functionality. International Dairy Journal, 17(11), 1278-1283. DOI: 10.1016/j.idairyj.2007.01.015

Neffe-Skocińska, K., Rzepkowska, A., Szydłowska, A. \& Kołożyn-Krajewska, D. (2018). Trends and possibilities of the use of probiotics in food production. In A. M. Holban \& A. M. Grumezescu (Eds.), Alternative and Replacement Foods (pp. 65-94): Academic Press.DOI:10.1016/B978-012-811446-9.00003-4

Norma Oficial Mexicana (NOM-086-SSA1),1994. Bienes y servicios. Alimentos y bebidas no alcohólicas con modificaciones en su composición. Especificaciones nutrimentales. Recuperado de http://www.salud.gob.mx/ unidades/cdi/nom/086ssa14.html

Norma Oficial Mexicana (NOM-051-SCFI/SSA1a),2010, Especificaciones generales de etiquetado para alimentos y bebidas no alcohólicas preenvasados-Información comercial y sanitaria. Recuperado de http://dof.gob.mx/ nota_detalle.php?codigo $=5137518 \&$ fecha $=05 / 04 / 2010$

Norma Oficial Mexicana (NOM-243-SSA1b),2010, Productos y servicios. Leche, fórmula láctea, producto lácteo combinado y derivados lácteos. Disposiciones y especificaciones sanitarias. Métodos de prueba. 
Recuperado de http://dof.gob.mx/normasOficiales/4156/ salud2a/salud2a.htm

Pakbin, B., Razavi, S. H., Mahmoudi, R. \& Gajarbeygi, P. (2014). Producing probiotic peach juice. Biotechnology Health Science, 1(3), e24683. DOI:10.17795/bhs-24683

Papizadeh, M., Rohani, M., Nahrevanian, H., Javadi, A. \& Pourshafie, M. R. (2017). Probiotic characters of Bifidobacterium and Lactobacillus are a result of the ongoing gene acquisition and genome minimization evolutionary trends. Microbial Pathogenesis, 111, 118131. DOI: https://doi.org/10.1016/j.micpath.2017.08.021

Pavli, F., Argyri, A. A., Nychas, G. J. E., Tassou, C. \& Chorianopoulos, N. (2018). Use of Fourier transform infrared spectroscopy for monitoring the shelf life of ham slices packed with probiotic supplemented edible films after treatment with high pressure processing. Food Research International, 106, 1061-1068. DOI:10.1016/j. foodres.2017.12.064

Pimentel, T. C., Madrona, G. S., Garcia, S. \& Prudencio, S. H. (2015). Probiotic viability, physicochemical characteristics and acceptability during refrigerated storage of clarified apple juice supplemented with Lactobacillus paracasei ssp. paracasei and oligofructose in different package type. LWT - Food Science and Technology, 63(1), 415-422. DOI:10.1016/j.lwt.2015.03.009

Ranadheera, C. S., Evans, C. A., Adams, M. C. \& Baines, S. K. (2013). Production of probiotic ice cream from goat's milk and effect of packaging materials on product quality. Small Ruminant Research, 112(1), 174-180. DOI:10.1016/j. smallrumres.2012.12.020

Ranadheera, C., Vidanarachchi, J., Rocha, R., Cruz, A. \& Ajlouni, S. (2017). Probiotic delivery through fermentation: Dairy vs. Non-dairy beverages. Fermentation, 3(4), 67.

Ranadheera, R. D. C. S., Baines, S. K. \& Adams, M. C. (2010). Importance of food in probiotic efficacy. Food Research International, 43(1), 1-7. DOI:10.1016/j. foodres.2009.09.009

Rascón, M. P., Huerta-Vera, K., Pascual-Pineda, L. A., ContrerasOliva, A., Flores-Andrade, E., Castillo-Morales, M., Bonilla, E. \& González-Morales, I. (2018). Osmotic dehydration assisted impregnation of Lactobacillus rhamnosus in banana and effect of water activity on the storage stability of probiotic in the freeze-dried product. LWT, 92, 490-496. DOI:10.1016/j.lwt.2018.02.074

Rathore, S., Salmerón, I. \& Pandiella, S. S. (2012). Production of potentially probiotic beverages using single and mixed cereal substrates fermented with lactic acid bacteria cultures. Food Microbiology, 30(1), 239-244. DOI: 10.1016/j.fm.2011.09.001

Rivera-Espinoza, Y. \& Gallardo-Navarro, Y. (2010). Non-dairy probiotic products. Food Microbiology, 27(1), 1-11. DOI:10.1016/j.fm.2008.06.008

Rojas-Graü, M. A., Soliva-Fortuny, R. \& Martín-Belloso, O. (2009). Edible coatings to incorporate active ingredients to fresh-cut fruits: a review. Trends in Food Science \& Technology, 20(10), 438-447. DOI:10.1016/j. tifs.2009.05.002

Romano, N., Tavera-Quiroz, M. J., Bertola, N., Mobili, P., Pinotti, A. \& Gómez-Zavaglia, A. (2014). Edible methylcellulosebased films containing fructo-oligosaccharides as vehicles for lactic acid bacteria. Food Research International, 64, 560-566. DOI:10.1016/j.foodres.2014.07.018

Russo, P., de Chiara, M. L., Vernile, A., Amodio, M. L., Arena, M. P., Capozzi, V. \& Spano, G. (2014). Fresh-cut pineapple as a new carrier of probiotic lactic acid bacteria. Biomedical Research International, 2014, 309183. DOI:10.1155/2014/309183

Salmerón, I., Thomas, K. \& Pandiella, S. S. (2015). Effect of potentially probiotic lactic acid bacteria on the physicochemical composition and acceptance of fermented cereal beverages. Journal of Functional Foods, 15, 106-115. DOI:10.1016/j.jff.2015.03.012

Sánchez, B., Fernández-García, M., Margolles, A., de los Reyes-Gavilán, C. G. \& Ruas-Madiedo, P. (2010). Technological and probiotic selection criteria of a bile-adapted Bifidobacterium animalis subsp. lactis strain. International Dairy Journal, 20(11), 800-805. DOI:10.1016/j.idairyj.2010.06.004

Sanders, M. E. \& Marco, M. L. (2010). Food formats for effective delivery of probiotics. Annual Reviews Food Science Technology, 1, 65-85. DOI:10.1146/annurev. food.080708.100743

Sharma, K., Mahajan, R., Attri, S. \& Goel, G. (2017). Selection of indigenous Lactobacillus paracasei CD4 and Lactobacillus gastricus BTM 7 as probiotic: assessment of traits combined with principal component analysis. Journal of Applied Microbiology, 122(5), 1310-1320. DOI:10.1111/jam.13426

Sheehan, V. M., Ross, P. \& Fitzgerald, G. F. (2007). Assessing the acid tolerance and the technological robustness of probiotic cultures for fortification in fruit juices. Innovative Food Science \& Emerging Technologies, 8(2), 279-284. DOI:10.1016/j.ifset.2007.01.007

Soukoulis, C., Behboudi-Jobbehdar, S., Yonekura, L., Parmenter, C. \& Fisk, I. D. (2014b). Stability of Lactobacillus rhamnosus GG in prebiotic edible films. Food Chemistry, 159, 302-308. DOI:10.1016/j.foodchem.2014.03.008

Soukoulis, C., Singh, P., Macnaughtan, W., Parmenter, C. \& Fisk, I. D. (2016). Compositional and physicochemical factors governing the viability of Lactobacillus rhamnosus GG embedded in starch-protein based edible films. Food Hydrocolloids, 52, 876-887. DOI:10.1016/j. foodhyd.2015.08.025

Soukoulis, C., Yonekura, L., Gan, H.-H., Behboudi-Jobbehdar, S., Parmenter, C. \& Fisk, I. (2014a). Probiotic edible films as a new strategy for developing functional bakery products: The case of pan bread. Food Hydrocolloids, 39, 231-242. DOI:10.1016/j.foodhyd.2014.01.023 
Tripathi, M. K. \& Giri, S. K. (2014). Probiotic functional foods: Survival of probiotics during processing and storage. Journal of Functional Foods, 9, 225-241. DOI:10.1016/j. jff.2014.04.030

Tsen, J.-H., Lin, Y.-P. \& King, V. A.-E. (2004). Fermentation of banana media by using $\kappa$-carrageenan immobilized Lactobacillus acidophilus. International Journal of Food Microbiology, 91(2), 215-220.

Vargas, L. A., Olson, D. W. \& Aryana, K. J. (2015). Whey protein isolate improves acid and bile tolerances of Streptococcus thermophilus ST-M5 and Lactobacillus delbrueckii ssp. bulgaricus LB-12. Journal of Dairy Science, 98(4), 22152221. DOI:10.3168/jds.2014-8869

Verruck, S., de Carvalho, M. W., de Liz, G. R., Amante, E. R., Vieira, C. R. W., Amboni, R. D. d. M. C. \& Prudencio, E. S. (2017). Survival of Bifidobacterium BB-12 microencapsulated with full-fat goat's milk and prebiotics when exposed to simulated gastrointestinal conditions and thermal treatments. Small Ruminant Research, 153, 48-56. DOI:10.1016/j.smallrumres.2017.05.008

Vinderola, C. G., Mocchiutti, P. \& Reinheimer, J. A. (2002). Interactions among lactic acid starter and probiotic bacteria used for fermented dairy products. Journal of Dairy Science, 85(4), 721-729. DOI:10.3168/jds.S00220302(02)74129-5

Xu, H., Jeong, H. S., Lee, H. Y. \& Ahn, J. (2009). Assessment of cell surface properties and adhesion potential of selected probiotic strains. Letters in Applied Microbiology, 49(4), 434-442. DOI:10.1111/j.1472-765X.2009.02684.x

Yao, G., Gao, P. \& Zhang, W. (2016). Complete genome sequence of probiotic Bacillus coagulans HM-08: A potential lactic acid producer. Journal of Biotechnology, 228, 71-72. DOI:10.1016/j.jbiotec.2016.04.045

Yu, Y.-J. Amorim, M., Marques, C., Calhau, C., \& Pintado, M. (2016). Effects of whey peptide extract on the growth of probiotics and gut microbiota. Journal of Functional Foods, 21, 507-516. DOI:10.1016/j.jff.2015.10.035

Zhang, L., Lou, Y. \& Schutyser, M. A. I. (2018). 3D printing of cereal-based food structures containing probiotics. Food Structure, 18, 14-22. DOI:10.1016/j.foostr.2018.10.002

Zhang, L., Taal, M. A., Boom, R. M., Chen, X. D. \& Schutyser, M. A. I. (2018). Effect of baking conditions and storage on the viability of Lactobacillus plantarum supplemented to bread. $L W T$, 87, 318-325. DOI:10.1016/j.lwt.2017.09.005 